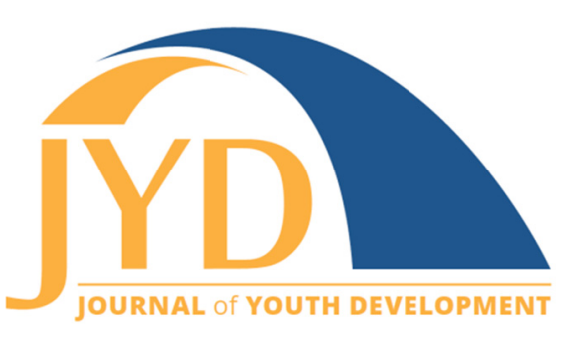

http://iyd.pitt.edu/ | Vol. 12 Issue 2 DOI 10.5195/jyd.2017.17 | ISSN 2325-4017 (online)

\title{
From Theory to Practice: A Critical Review of Positive Youth Development Program Frameworks
}

\author{
Mary Elizabeth Arnold \\ Oregon State University \\ mary.arnold@oregonstate.edu \\ Ben Silliman \\ North Carolina State University \\ bsillim@ncsu.edu
}

\begin{abstract}
Many positive youth development (PYD) programs are based on a particular PYD framework as a method for describing the program's intention and expected outcomes. This paper presents a critical review of eight select program frameworks that are commonly used to describe PYD programs. The review reveals considerable variation in the science supporting these frameworks, with corresponding variability in their programmatic application. To account for this variation, the frameworks were grouped into three categories based on the science and context in which they were developed. After a review of the historical and organizational context for the need and use of program frameworks, we present brief reviews of the frameworks, then close by discussing implications for practice, research, and policy.
\end{abstract}

Key words: positive youth development (PYD), PYD frameworks, youth program outcomes

\section{Introduction}

As the field of positive youth development (PYD) has matured, frameworks to describe program theory and identify program outcomes have been developed. There is considerable variation in the science supporting these frameworks, however, and even greater variability in the application of the frameworks to guide PYD programming at the point-of-service level. As a result, local programs are often developed based on limited understanding of a framework's theory of change and action, resulting in programming that may wander far from the PYD elements purported to be guiding the program.

(cc) EY $_{\text {EY }}$ New articles in this journal are licensed under a Creative Commons Attribution 4.0 License. This journal is published by the University Library System, University of Pittsburgh and is cosponsored by the University of Pittsburgh Press. The Journal of Youth Development is the official peer-reviewed publication of the National Association of Extension 4-H Agents and the National AfterSchool Association. 


\section{A Critical Review of PYD Program Frameworks}

In an effort to improve the consistent and intentional use of frameworks in 4-H programs, which is the largest youth-serving organization in the United States, a committee ${ }^{1}$ was commissioned to select and examine prominent positive youth development frameworks for scientific validity, theories of change and action, and utility for 4- $\mathrm{H}$ youth development programming. This article summarizes the review of the selected PYD frameworks, which we think has applicability to many other positive youth development organizations as well. After a review of the historical and organizational context for the need and use of program frameworks, we present brief reviews of eight frameworks, and then close by discussing implications for practice, research, and policy.

\section{Setting the Stage: The 4-H Program as an Example}

While PYD frameworks have tremendous, if underutilized, potential to guide the development of effective programs, their initial development was driven by increased pressure to demonstrate the impact of youth programming (Arnold \& Cater, 2011). The emerging body of youth development research and pressures for accountability led to increased professional development in the areas of program planning and evaluation (Arnold \& Cater, 2011). In the 1990s advocacy for intentional, research-based programming was accentuated as government and program funders increased expectations for program outcomes (Arnold \& Cater, 2016). In addition, special Extension initiatives such as Children, Youth, and Families at Risk (CYFAR) and Extension Foods and Nutrition Expanded Programming (EFNP), and the 4-H Mission Mandates intensified the integration of research in Extension youth program planning and evaluation.

Subsequent public and private investments in research resulted in exponential growth in published positive youth development research and the development of nascent theoretical frameworks (Small \& Memmo, 2004). Building on these developments, youth organizations began professional development efforts to educate and prepare professional staff and identify competencies for youth workers (e.g., Stone \& Beiber, 1997). More recently, 4-H leadership in the founding of the Journal of Youth Development, promotion of the 4-H Essential Elements as a basic framework for 4-H programs (Kress, 2005), and the sponsorship of the 4-H Study of Positive Youth Development (Lerner \& Lerner, 2013) further expanded reflection-and action-

\footnotetext{
${ }^{1}$ The authors wish to acknowledge the contributions of the committee members who reviewed one or more of the frameworks. Complete reviews of the frameworks that are summarized in this article are presented in full in Arnold et al. (2016).
} 


\section{A Critical Review of PYD Program Frameworks}

on frameworks to guide youth programming in 4-H. Simultaneous developments in evaluation capacity-building that focused on utilizing PYD theory to articulate program logic models further integrated training in program planning and evaluation with youth programming (Arnold, 2006; Silliman \& Guin, 2012; Taylor-Powell \& Boyd, 2008).

\section{4-H Program Quality and Accountability}

Despite these advances, the consensus of the PYD committee experts convened by the national 4-H leadership was that local 4-H programs are still not guided consistently by positive youth development frameworks and the research supporting the frameworks (L. Lauxman, personal communication, February 13, 2015). The committee's experience working with 4-H programs across the country suggested that local programs were more likely to be based on a few PYD principles (e.g., connections to caring adults, self-directed project work, youth-driven leadership) than systematic application of a PYD framework. Some of the gap in translating research into practice is due to limited understanding of PYD research and training, high staff turnover, the intensive time demands of youth work, and an over-focus on program activities without a clear understanding of the relationship of activities to overall program goals (Arnold \& Cater, 2016). In addition, even with the most common frameworks utilized by the 4-H program, there remains a lack of specific guidance for the application of the framework into practice (Heck \& Subramaniam, 2009).

\section{Methods and Procedures}

This review focused on PYD frameworks that aligned with the stated purposes and goals of PYD programs: (a) promoting positive youth development by focusing on the situations and processes that facilitate healthy development (Small \& Memmo, 2004); (b) helping youth reach full potential (Roth, Brooks-Gunn, Murray, \& Foster, 1998); (c) providing support and opportunities for success (Gambone, Klem, \& Connell, 2002); (d) building community capacity (Benson, 1997; Connell, Gambone, \& Smith, 1998; Eccles \& Gootman, 2002); and (e) approaching youth as assets to be developed rather than problems to be fixed (Pittman \& Irby, 1996; Pittman \& Zeldin, 1995).

Using these criteria as a guide, the committee first selected frameworks used solely within the 4-H program (e.g., the Essential Elements and Targeting Life Skills frameworks) and broader frameworks that are frequently used to describe 4-H (e.g., the 5 Cs and Developmental Assets 


\section{A Critical Review of PYD Program Frameworks}

frameworks), as well as frameworks adopted for use in 4-H programs (e.g., California and Oregon 4-H program models). From there, the committee perused the literature for wellarticulated models that were not commonly used in 4-H (e.g., the Youth Community Action Framework). Reviewers agreed that the 11 frameworks chosen for review offered a diverse but manageable knowledge base for planning and implementing youth programs. This article focuses on the eight models most useful to other community-based youth programs.

\section{Criteria for Review of Frameworks}

Youth development frameworks articulate the internal and external factors and their interactions that support optimal development in youth (Durlak, 1997). According to Heck and Subramaniam (2009) frameworks have four purposes: (a) to give direction and purpose to a program; (b) to guide program activities toward outcome achievement; (c) to identify logical and clear program outcomes; and (e) to guide program evaluation.

In addition, Heck and Subramaniam (2009) outlined three criteria for reviewing frameworks:

- Validity of the framework-this criterion focuses on the science behind the framework that supports the efficacy of its use for PYD, and evidence from research literature that demonstrates the framework leads to positive youth outcomes.

- Utility of the framework-this criterion focuses on the extent to which the framework is used in youth development research and evaluation as well as the specificity and measurability of the constructs.

- Universality-this criterion considers the applicability of the framework for varying populations.

Well developed frameworks are built on sound theory that underscores the processes through which a program will achieve its stated outcomes (Chen, 2004). Program theory contains two critical aspects: (a) the program theory of change that articulates the way in which a change is to come about; and (b) the program theory of action that refers specifically to what actions need to happen, at what level of success, for the program outcomes to be achieved (Funnell \& Rogers, 2011). A program's theory and description of the activities critical to effectiveness are key ingredients for translating concepts into program practice (Arnold, 2015). For instance, broader theories describe the "big picture" behind development and programming, but need to be translated into specific outcomes and strategies to reach those outcomes in order to be useful to the local program leaders. Thus, we added criteria related to program theory and action to the list of framework review criteria used by Heck and Subramaniam (2009). Finally, 


\section{A Critical Review of PYD Program Frameworks}

because this work was commissioned by the National 4-H Program, reviewers addressed the utility and overall value of each framework for $4-\mathrm{H}$ programming

\section{Grouping the Frameworks}

Once the frameworks for inclusion were identified it became clear that they were not all the same. While each framework has value and applicability for positive youth development programs, we were hesitant to lump them together because of the considerable differences in how each framework was developed. To proceed as if they were homogeneous would undermine our goal of helping practitioners distinguish and use frameworks purposefully. We felt grouping them into categories would aid others in understanding the genesis and intended uses of the framework. Grouping also enabled review of the frameworks in the context in which they were developed. For example, empirically-tested frameworks met the validity criteria in different ways than other frameworks, but all could be assessed for a theory of change and action as well as translation into practical program use. We retained these distinctions in purposes, types and levels of evidence, and unique contexts in which they were developed, while admitting comparisons on common criteria such as theories of change and action, utility of use in 4-H programs, and universality for varying populations. Thus frameworks were grouped as follows:

Research-driven frameworks. We considered three frameworks developed through rigorous literature review and confirmatory analysis of youth data to be research-driven:

- The Community Action Framework for Youth Development

- Developmental Assets Framework

- Developmental Systems Theory: The 5 Cs of Positive Youth Development

Research-referenced frameworks. Frameworks that emerged from a systematic review of youth development and/or practice literature include:

- Character Counts!

- The Essential Elements of 4-H Youth Development

- $\quad$ Targeting Life Skills

Research-adapted frameworks. Frameworks adapted from one or more lines of youth development research for use in specific program contexts include:

- California 4-H Youth Development Framework 


\section{A Critical Review of PYD Program Frameworks}

- $\quad$ Oregon 4-H Youth Development Framework

\section{Reviewers and Procedure}

Reviewers included 4-H professionals from across the 4-H system with specialized training and practical experience in PYD, program theory, and evaluation. Reviewers were recruited by invitation and word of mouth. Reviewers were assigned frameworks based on expertise and experience with a framework. After a brief orientation to the task, reviewers examined the assigned frameworks based on the criteria specified above and submitted a draft review that was edited by the authors and revised before completion of the final draft.

\section{Community Action Framework for Youth Development (Gambone, Klem, \& Connel, 2002)}

This framework identifies key supports and opportunities in community programs and other youth contexts that assuage risk and promote thriving paths for adolescents. Supports and opportunities include meeting basic needs, relationships with caring adults and peers, challenging activities, meaningful involvement, and safety. Supports and opportunities help youth be productive; connect positively with others; navigate adolescent challenges; and become self-sufficient, adjusted and contributing, resourceful and adaptable young adults.

\section{Supporting science}

Developed from two longitudinal studies, rigorous meta-analysis, and community-based testing, the model highlights the importance of supports and opportunities at multiple levels of a youth's developmental context. The Community Action framework provides research on risk and thriving thresholds and the mix of program and community influences that aids in targeting programs to specific settings.

\section{Theory of change and action}

The Community Action framework is built on a developmental-ecological framework that identifies categories of supports (e.g., caring adults) and opportunities (e.g., challenging activities, meaningful involvement) rather than specific types of programs (e.g., sports, arts, 4$\mathrm{H}$, or Scouts) that contribute to present and future productivity, connection, and navigation. Practitioners will need to tailor activities to specific local outcomes (e.g., STEM, health), 


\section{A Critical Review of PYD Program Frameworks}

emphasizing relational as well as instrumental outcomes. The framework highlights the importance of capacity-building and collaboration at community and organization-levels, not only as context but as prerequisite for asset development. Thus actions before and beyond direct work with youth may be critical to initiating or sustaining work with youth.

\section{Utility}

This framework offers a comprehensive, community-based approach linking diverse riskprevention and/or positive youth development factors across adolescence into adulthood. A variety of short-term resources, strategies, and outcomes can be adapted within this framework to promote individual, program, and/or community change.

\section{Recommendations}

The Community Action framework provides strong social science and program theory adapted to both long-term and specifically-targeted initiatives with pre-teens and teens consistent with PYD principles and practices.

\section{Developmental Assets Framework (Benson, Scales, \& Syvertsen, 2011)}

This framework, developed by Search Institute, identifies a broad range of external and internal factors descriptive of short- and long-term developmental assets in children, adolescents, and young adults that reduce risk and promote thriving and resilience. Search Institute employs a wealth of research-tested assessments, curricula, and consultation strategies to adapt the broader 40 Assets model to a wide range of community-, program-, and individual-level interventions.

\section{Supporting science}

Over the past 30 years, the Developmental Assets framework is arguably the most thoroughly tested, adapted, and refined research and applied practice model, with multiple applications for diverse audiences and settings globally. A variety of community, organization, and individuallevel assessments provide useful tools for assessment and evaluation supported by a growing body of longitudinal and cumulative data and related insights on youth development and programming. 


\section{A Critical Review of PYD Program Frameworks}

\section{Theory of change and action}

Search Institute provides numerous examples of the consultation and testing approach by which they determine the specific factors and strategies to foster change for children and youth at specific developmental stages and in specific cultural contexts The resulting place/programspecific theory of action focuses on priorities for youth (which risks and assets to address) and capacities of organizations and communities (which resources and conditions facilitate change). Consultation with local partners, use of research-based curricula and training, and pre- and post-testing serve to tailor, monitor, and evaluate programs for targeted outcomes.

\section{Utility}

The Developmental Assets framework, assessments, process, and resource materials are compatible with PYD program principles and practices at the community level. In addition, because of its broad dissemination this framework is likely familiar to many youth development programs. A variety of short-term resources and strategies can be adapted within this framework. Process and outcome indicators from extensive testing offer promising tools for monitoring individual, program, and community change.

\section{Recommendations}

The scientific depth and practical utility of the Developmental Assets model provide extensive resources for assessment, planning, implementation, and evaluation for programs serving children and youth, schools and out-of-school programs, and communities. The framework has proven useful for youth programs and their community partners for over 20 years. The Developmental Assets framework is likely to remain among the most useful approaches to "big picture" and "focused program" positive youth development for the foreseeable future.

\section{Developmental Systems Theory - The Five Cs (Lerner \& Lerner, 2013)}

This model proposes that programs consisting of meaningful leadership opportunities, positive and sustained relationships, and activities that build critical life skills lead to five key developmental outcomes: caring, character, connection, confidence and competence, the "5Cs." The Five Cs model was developed and extensively tested longitudinally over eight waves of annual data collection with diverse youth. 


\section{A Critical Review of PYD Program Frameworks}

\section{Supporting science}

The Five Cs model is well-tested with a psychometrically-supported structure. The testing of this model has resulted in numerous doctoral dissertations and scholarly articles, book chapters and monographs written largely for a methodologically-advanced audience. The Five Cs model is arguably the most established model used in the academic study of PYD.

\section{Theory of change and action}

This model presents a clear theory of change, from program inputs leading to positive youth development outcomes, to program impacts of increased contribution and reduced youth risk behavior. The theory of action highlights critical activities including skill building, positive relationships between youth and adults, and opportunities for youth to use the skills they learn through leadership and active contributions to community. However, these broad categories of action do not provide enough specificity in terms of actions, intensity, and context for the model to be replicated easily.

\section{Utility}

One of the key strengths of the Five Cs model is that it was tested on a large, diverse sample of youth. And because of the extensive amount of published literature on the model, the outcomes of caring, character, connection, confidence and competence comprise one of the most common ways that PYD is presented in program descriptions. However, there has been little translation of the model into on-the-ground practice, nor integration of the model into professional development resources for PYD professionals. Furthermore, the study data offer few insights into the processes that drive outcomes; this limits the practical utility of the model until more work is done to guide the translation of the model into effective practice.

\section{Recommendations}

Emphasis must be placed on translating the model into consistent practice across PYD programs, by helping 4-H program developers to understand the structure of the model and how it is useful to describe their work. The model also needs to be translated into effective practice. For example, how do youth leadership experiences lead to the development of the 5Cs? PYD professionals need a clear understanding of the fidelity to practice that must be followed in order to ensure that the leadership experiences lead to enhanced PYD. 


\section{Character Counts! (Josephson Institute of Ethics, 2007)}

This framework is based on a belief that certain teachable virtues (e.g., trustworthiness, respect, responsibility, fairness, caring, and citizenship) ought to be inculcated in youth and sustained as hallmarks of public life. Consistent practice of such virtues is regarded as a path to reducing risk behavior and enhancing positive interaction, resulting in individual and societal benefits.

\section{Supporting science}

The Character Counts! materials align with, but do not specifically document, research on ethics or moral development. The evidence presented to support the framework's effectiveness is largely based on surveys of educators and participants, case studies, and school records on academic and behavioral data. The Character Counts framework utilizes a standard protocol entitled Teach-Enforce-Affirm-and-Model (TEAM) for training and rehearsing character traits. TEAM is loosely based on educational psychology, but largely untested.

\section{Theory of change and action}

Learning and consistently applying character values and behavioral skills associated with virtues-in an environment that reinforces these traits-is viewed as critical to continuous and consistent practice. The TEAM strategy is designed to introduce, practice, and monitor these values and skills in youth at an impressionable age.

\section{Utility}

The Character Counts! framework is consistent with many practical and ethical values of PYD programs. The framework overlaps with the leadership and life skills seen as integral to the immediate and future work, family, and community success of 4-H youth.

\section{Recommendations}

The Character Counts! framework offers affirmation and training in virtues and behaviors consistent with youth development research generally, but not based on empirical research. 


\section{The Essential Elements of 4-H (Kress, 2005)}

This framework was proposed explicitly for the 4-H program by former national 4-H program leader, Cathann Kress. The framework is a "distillation" of the eight critical elements of the 4-H program identified in the National 4-H Impact Assessment Project (Peterson et al., 2001) into the four "essential" elements of belonging, mastery, independence and generosity. The four elements match those presented in the Circle of Courage (Brendtro, Brokenleg, \& Van Bockern, 1990).

\section{Supporting science}

The Essential Elements framework is used extensively in 4-H programs, but has never been tested as a framework or model. Furthermore, there is confusion as to whether the essential elements are program quality indicators or youth outcomes. The framework aligns with SelfDetermination Theory (SDL) proposed by Deci and Ryan (2008), who submit that developing relatedness, competence and autonomy is key to healthy development. Validity of SDL theory has been demonstrated with children and adolescents, lending support to the validity of the Essential Elements as a conceptual framework.

\section{Theory of change and action}

The Essential Elements of 4-H framework implicitly uses a social learning approach in which watching and participating over time lead to key outcomes. A training curriculum on the Essential Elements for 4-H professional and volunteers stresses identification of prevention, education, and/or youth development goals and inclusion of all four elements, but provides few specifics on strategies for implementation or targeted program outcomes.

\section{Utility}

The Essential Elements framework is relatively easy to understand and interpret and has relevancy and utility for all PYD programs, despite its 4-H branding. However, lack of detail on program implementation and evaluation limits its usefulness. 


\section{A Critical Review of PYD Program Frameworks}

\section{Recommendations}

The Essential Elements framework provides a valuable introduction to PYD program qualities and outcomes across diverse settings, but lacks articulation and evidence needed to guide clear program implementation. In order for the framework to be fully useful to PYD programs, more work needs to be done to place the framework within a detailed program theory of change, with attention to specific actions that connect the four elements to program outcomes.

\section{Targeting Life Skills (Hendricks, 1998)}

Targeting Life Skills is another framework developed explicitly for the 4-H program. The initial intent of this framework was to serve as a guide for evaluating a wide range of life skills taught within 4-H programs in Iowa, and subsequently widely adopted in other state 4-H programs. The 35 identified life skills are organized to illustrate their connection to the four Hs (Head, Heart, Hands, Health). The framework focuses primarily on the individual and small group level, and does not address program or community ecosystems or long-term versus short-term growth.

\section{Supporting science}

While there is research supporting the importance of some of the identified life skills, and the framework is broadly related to PYD themes, there is no empirical validation for the framework nor is there any empirical confirmation of the organization of the skills into the four Hs. While widely used across the 4- $\mathrm{H}$ system, the Targeting Life Skills framework is more descriptive of skills developed in PYD programs than predictive of general positive youth development.

\section{Theory of change and action}

The Targeting Life Skills model advocates use of experiential learning and developmentally appropriate curricula and offers a detailed program planning guide. These resources can support an action model but program developers must draw a theory of change and action from other sources (e.g., developmental theories, research in a specific skill area) to articulate specific strategies for specific audiences. 


\section{Utility}

Although the Targeting Life Skills framework is widely used in the 4-H program, it is similarly useful to other PYD programs. However, the planning, implementation, and evaluation in life skills would be significantly enhanced if augmented by application of research on specific skills (e.g., goal setting and persistence) and program models (e.g., frequency, intensity, and duration of programming needed).

\section{Recommendations}

The Targeting Life Skills framework provides a useful description of key life skill outcomes for PYD programs, but without a clear program theory of change and action, as well as supporting science, it falls short of the requirements for a program framework. As such, this framework is most useful for identifying desired learning and action outcomes of PYD programs.

\section{California 4-H Youth Development Framework (Dogan, Miner, Worker, Bottoms, Hill, \& Mautte, n.d.)}

Developed for use in the California 4-H program, this framework emphasizes the use of developmental theory and science to create intentional program processes that help youth reach their full potential. The framework outlines youth organizational, youth development, and educational practices that underscore the program processes that lead to the achievement of stated program outcomes.

\section{Supporting science}

The framework is derived from several strands of adolescent research supporting the connection of practices to youth development outcomes. The youth educational outcomes identified in the model are a combination of youth development and program content outcomes that are supported through research.

\section{Theory of change and action}

The theory of change is based on organizational and service-level program practices, educational content, and strategies for learning that include an ecological approach to youth development. Program activities are based on educational strategies and practices that have 


\section{A Critical Review of PYD Program Frameworks}

been well-established. The inclusion of learning methods, such as experiential and service learning connects the program activities with the larger theory of positive youth development.

\section{Utility}

The framework utilizes prominent strands of youth development research and practice. The inclusion of educational approaches and methods strengthens the framework's theory of action, making the model particularly useful for a variety of PYD programs beyond 4-H.

\section{Recommendations}

The California 4-H framework is based on sound research, and presents a universal and useful framework for the 4-H program. The psychometric and predictive qualities of the framework are currently being tested in California, the results of which could lend further support for adoption of the framework across the 4-H system.

\section{The Oregon 4-H Program Model (Arnold, 2014)}

This framework describes developmental outcomes in terms of six thriving indicators proposed by Search Institute (2014). The thriving indicators are drawn from major bodies of research on adolescent development, and are conceptually consistent with other descriptions of positive development outcomes. The Oregon 4-H framework articulates the connections between traditional 4-H activities and strategies and the research that supports the developmental impact of them.

\section{Supporting science}

The Oregon 4-H program model draws on extensive research in the field of youth development, particularly in the areas of youth program quality, developmental assets and thriving, and developmental systems theory. As such, the individual constructs of the model are drawn from the latest and most comprehensive understanding of positive youth development. Psychometric testing of the framework's structure and predictive validity is currently underway.

\section{Theory of change and action}

There is a clear theory of change based on social learning in programs that are centered on PYD principles and supportive relationships. Actions that put the program theory into motion 


\section{A Critical Review of PYD Program Frameworks}

include helping youth discover and grow their interests in a topic, providing a high quality youth program experience, promoting and facilitating developmental relationships between youth and adults and among peers, and ensuring that youth participate in $4-\mathrm{H}$ at a depth sufficient to promote thriving.

\section{Utility}

The Oregon framework situates the traditional 4-H program in current research in child and adolescent development, particularly in terms of connecting more traditional aspects of 4- $\mathrm{H}$ to current developmental theory. The psychometric and predictive qualities of the framework are currently being tested in Oregon, the results of which could lend further support for adoption of the framework across the 4-H system. Unbranded, the frameworks has universal utility for other PYD programs as well.

\section{Recommendations}

The Oregon 4- $\mathrm{H}$ framework is based on sound research, and presents a universal and useful framework for PYD programs. A more detailed presentation of the theory of action (e.g., the program activities that put the framework into motion) would be useful to understanding the relative contribution of $4-\mathrm{H}$ activities to the overall program theory.

\section{Conclusion and Recommendations}

This article presented brief reviews of eight positive youth development frameworks based on supporting developmental science, program theory of change and action, and utility. A final criterion considered the recommended use of the frameworks specifically for the 4-H program. While admittedly, this final criterion is not universal to other programs, we argue that the strengths and concerns of each model are applicable to many PYD programs. This is primarily because of a universal problem with the utility of all of the frameworks presented: the lack of a detailed program theory of change that provides enough specificity for PYD programs to develop and implement programs with fidelity to the model.

As Arnold (2015) pointed out, one of the main concerns with planning, implementing and evaluating PYD programs is effective and practical translation of frameworks into program practice. The science and supporting evidence behind many of the frameworks are strong, and in some cases extensive. This translational gap between the work of the research scientists and 


\section{A Critical Review of PYD Program Frameworks}

program practitioners leads to uneven, and in some cases incorrect application of the frameworks in youth development programs.

\section{Implications for Practice}

Development and translation of program theories to local practice must be matched by growth of programs beyond short-term activities. Intentional and sustained programs yield the greatest and most diverse impacts (Walker, 2006), yet such continuity is difficult to sustain in many PYD settings. Alternatively, community programs focused on program quality and fidelity to research-based principles can show evidence of merit with reasonable inference to worth (Arnold, Braverman \& Cater, 2016; Blyth, 2011).

Translation of frameworks into consistent, high-quality program implementation that leads to intentional outcomes across program offerings is most likely to be advanced through investments in professional development and preparation of front-line staff in planning and implementation (Arnold \& Cater, 2016; Arnold, Braverman, \& Cater, 2016). Staff or volunteers who know when and how to implement the "active ingredients" of programs (practical steps in the theory of action) are also likely to manage, evaluate, and learn from programs and relate to youth participants more effectively. With increasing effectiveness, program staff will be more likely to continue and grow in their roles, benefitting participants through enhanced skills and sustained caring, and the program through creative application and refinement of program models.

\section{Implications for Research}

Most frameworks can be refined and clarified through expanded literature review and empirical testing. Risk and protective factors, assets and traits of positive youth development are wellestablished across multiple models. Less well-established are specific mechanisms that facilitate change for specific participants in specific settings or conditions. Knowing where, when, how, and how much to make a difference is critical to effective practice and necessary for improving frameworks. There is some positive movement in this direction with the research currently being conducted in the California and Oregon 4-H programs. California is engaged in empirical research, including a randomized control study, of the California 4-H model with various audiences. Oregon is currently collecting data from youth to investigate the structure and accuracy of the Oregon 4-H model, with a special emphasis on the elements that make up a 


\section{A Critical Review of PYD Program Frameworks}

high quality 4-H program, and the connection between the program's developmental context (Roth \& Brooks-Gunn, 2016) and youth outcomes. Effective dissemination and utilization of this research could result in the adoption of these frameworks to guide other PYD programs.

\section{Implications for Policy}

While continued support is needed for development and testing of PYD models, this article identifies a most urgent need for translation of foundational knowledge into effective practice. At present, 4-H, like many youth organizations, lacks specialists with the expertise and capacity to translate existing models into consistent, high quality programs across the organization. Further investment in applied youth development specialists is needed to translate and apply program frameworks to new settings or audiences and to explore the conditions and mechanisms that make a difference on the program or individual level. Wholesale organizational change may not be necessary; strategically-selected investments and pilot projects or participants can drive innovation and improvement.

Effective translation, utilization, and implementation of PYD frameworks grounded in developmental science impact the positive results of youth programs. Using frameworks for program development, improvement, and accountability enhances the public value of youth programs. Investments in frameworks improvement and innovation help programs survive and thrive, expand audiences, attract funding, and build a reputation for effectiveness. Investment in expertise for translating research into effective practice and professional development of front-line staff to implement programs with knowledge, skill, and fidelity holds the best potential to improve and refine programs. Such an investment reflects our responsibility for ensuring that the results of research make a difference in the real lives of youth, families, and communities.

\section{References}

Arnold, M. E. (2006). Developing evaluation capacity in Extension 4-H field faculty: A framework for success. American Journal of Evaluation, 272), 257-269.

Arnold, M. E. (2014). The Oregon 4-H Program Model. Corvallis, OR: Oregon State University 4-H Youth Development Program.

Arnold, M. E. (2015). Connecting the dots: Improving Extension program planning with program umbrella models. Journal of Human Sciences and Extension, 3(2), 48-67. 


\section{A Critical Review of PYD Program Frameworks}

Arnold, M. E., Braverman, M. T., \& Cater, M. (2016). Rethinking evaluation capacity in youth development programs: A new approach for engaging youth workers in program evaluation. In B. Kirshner and K. Pozzoboni (Eds.). The Changing Landscape of Youth Workers (pp. 193-210). Scottsdale, AZ: Information Age Press.

Arnold, M. E., \& Cater, M. (2011). From then to now: Emerging directions for youth program evaluation. Journal of Youth Development, 6(3), 82-94.

Arnold, M. E., \& Cater, M. (2016). Program theory and quality matter: Changing the course of Extension program evaluation. Journal of Extension, 54(1). Retrieved from: http://www.joe.org/joe/2016february/a1.php

Arnold, M. E., Silliman, B., Bledsoe, L., Diaz, L., Johnson, J., Lauxman, L., ... White, D. J. (2016). 4-H program quality and accountability taskforce PYD frameworks committee final report. Unpublished manuscript.

Brendtro, L. Brokenleg, M., Van Bockern, S. (1990). Reclaiming Youth at Risk: Our Hope for the Future. Bloomington, IN: National Education Service.

Benson, P. (1997). All kids are our kids: What communities must do to raise caring and responsible children and adolescents. San Francisco, CA: Jossey Bass.

Benson, P. L., Scales, P. C., \& Syvertsen, A. K. (2011). The contribution of the developmental assets framework to positive youth development theory and practice. Advances in Child Development and Behavior, 41, 197-230.

Blyth, D. (2011). The future of youth development: Multiple wisdoms, alternate pathways, and aligned accountability. Journal of Youth Development, 6(3), 165-180.

Chen, H. (2004). Practical program evaluation: Assessing and improving planning, implementation, and effectiveness. Thousand Oaks, CA: Sage.

Connell, J., Gambone, M., \& Smith, Y. (1998). Youth development in community settings: Challenges to our field and approach. Philadelphia, PA: Institute for Reform in Education.

Eccles, J. \& Gootman, J. A. (2002). Community programs to promote youth development. Washington, DC: National Research Council.

Funnell, S. C., \& Rogers, P. J. (2011). Purposeful program theory: Effective use of theories of change and logic models. San Francisco, CA: Jossey Bass.

Deci, E. L. \& Ryan, R. M. (2008). Self-determination theory: A macrotheory of human motivation, development and health. Canadian Psychology, 49(3), 182-185.

Dogan, S., Miner, G., Worker, S., Bottoms, M., Hill, R., \& Mautte, S. (n.d.). UC4-H Youth Development Program Framework. Davis, CA: University of California Agriculture and Natural Resources.

Durlak, J. (1997). Success prevention programs for children and adolescents. New York, NY: Plenum Press. 


\section{A Critical Review of PYD Program Frameworks}

Gambone, M. A., Klem, A. M., \& Connell, J. P. (2002). Finding out what matters for youth: Testing key links in a community action framework for youth development. Philadelphia, PA: Youth Development Strategies Inc.

Heck, K. E., \& Subramaniam, A. (2009). Youth development frameworks (University of California 4-H Center for Youth Development Monograph). Davis: University of California.

Hendricks, P.A. (1998). Developing youth curriculum using the targeting life skills model: Incorporating developmentally appropriate learning opportunities to assess impact of life skill development. Ames: Iowa State University.

Josephson Institute of Ethics. (2007). Character Counts! Works And here is the data to prove it. Retrieved from https://charactercounts.org/wp-content/uploads/2014/02/Evidance_that_CC_Works.pdf

Kress, C. (2005). Essential Elements of positive youth development. In Strengthening Positive Youth Development Environments (pp. 20-23). Madison: University of Wisconsin Extension 4-H Program.

Lerner, R. M., Dowling, E. M., \& Anderson, P. M. (2003). Positive youth development: Thriving as a basis of personhood and civil society. Applied Developmental Science, 7, 172-180.

Lerner, R. M., \& Lerner, J. V. (2013). The positive development of youth: Comprehensive findings from the 4-H study of positive youth development. Washington, DC: National 4-H Council.

Peterson, B., Gerhard, G., Hunter, L., Marek, L., Phillips, C., \& Titcomb, A. (2001). Prepared and engaged youth serving American communities: The National 4-H Impact Assessment Project. Washington, DC: National 4-H Headquarters.

Pittman, K. \& Irby, M. (1996). Preventing problems or promoting development: Competing priorities or inseparable goals? Baltimore, MD: International Youth Foundation.

Pittman, K. \& Zeldin, S. (1995). Premises, principles, \& practices: Defining the why, what and how of promoting youth development through organizational practice. Washington, DC: Academy for Educational Development, Center for Youth Development and Policy Research.

Rennekamp, R. A., \& Arnold, M. E. (2009). What progress, program evaluation? Reflections on a quartercentury of Extension evaluation practice. Journal of Extension [Online], $4 \pi 3)$. Retrieved from: http://www.joe.org/joe/2009june/comm1.php

Roth, J., Brooks-Gunn, J., Murray, L., \& Foster, W. (1998). Promoting healthy adolescents: Synthesis of youth development program evaluations. Journal of Research on Adolescence, 8(4), 423-459.

Roth, J. L., \& Brooks-Gunn, J. (2016). Evaluating youth development programs: Progress and promise. Applied Developmental Science, 20(3), 188-202.

Small, S. \& Memmo, M. (2004). Contemporary models of youth development and problem prevention: Toward an integration of terms, concepts, and models. Family Relations, 53(1), 3-11.

Search Institute (2014). The Search Institute model of youth thriving orientation: Overview of its evolution through recent funding from the Thrive Foundation for Youth. Unpublished manuscript. 
Journal of Youth Development | http://jyd.pitt.edu/ | Vol. 12 Issue 2 DOI 10.5195/jyd.2017.17

A Critical Review of PYD Program Frameworks

Silliman, B., \& Guin, A. (2012). Tracking evaluation capacity-building for youth professionals. Journal of Youth Development, $\pi 1$ ), 24-34.

Stone, B. B., \& Beiber, S. (1997). Competencies: A new language for our work. Journal of Extension, 35(1). Retrieved from: http://www.joe.org/joe/1997february/comm1.html

Taylor-Powell, E. \& Boyd, H.H. (2008). Evaluation capacity in complex organizations. In M. T. Braverman, M. Engle, M. E. Arnold, \& R. A. Rennekamp (Eds.), Program evaluation in a complex

organizational system: Lessons from Cooperative Extension. New Directions for Evaluation, 120, 55-69.

Walker, J. (2006). Intentional youth programs: Taking theory to practice. New Directions in Youth Development, 112, 75-92. 